\title{
Do-not-resuscitate orders in patients with community-acquired pneumonia: a retrospective study
}

\author{
Gertrud Baunbæk Egelund ${ }^{1,2,3^{*}} \mathbb{D}$, Andreas Vestergaard Jensen ${ }^{1,2^{*}}$, Pelle Trier Petersen ${ }^{1}$, Stine Bang Andersen ${ }^{1}$, \\ Bjarne Ørskov Lindhardt ${ }^{2,4}$, Gernot Rohde ${ }^{3,5}$, Pernille Ravn ${ }^{2,6}$ and Christian von Plessen ${ }^{7,8}$
}

\begin{abstract}
Background: To investigate the use of do-not-resuscitate (DNR) orders in patients hospitalized with communityacquired pneumonia (CAP) and the association with mortality.

Methods: We assembled a cohort of 1317 adults hospitalized with radiographically confirmed CAP in three Danish hospitals. Patients were grouped into no DNR order, early DNR order ( $\leq 48 \mathrm{~h}$ after admission), and late DNR order ( $>48 \mathrm{~h}$ after admission). We tested for associations between a DNR order and mortality using a cox proportional hazard model adjusted for patient and disease related factors.

Results: Among 1317 patients 177 (13\%) patients received a DNR order: 107 (8\%) early and 70 (5\%) late, during admission. Patients with a DNR order were older (82 years vs. 70 years, $p<0.001$ ), more frequently nursing home residents ( $41 \%$ vs. $6 \%, p<0.001)$ and had more comorbidities (one or more comorbidities: $73 \%$ vs. $59 \%, p<0.001$ ). The 30-day mortality was $62 \%$ and $4 \%$ in patients with and without a DNR order, respectively. DNR orders were associated with increased risk of 30-day mortality after adjustment for age, nursing home residency and comorbidities. The association was modified by the CURB-65 score Hazard ratio (HR) 39.3 (95\% Cl 13.9-110.6), HR 24.0 (95\% Cl 11.9-48,3) and HR 9.4 (95\% Cl: 4.7-18.6) for CURB-65 score 0-1, 2 and 3-5, respectively.

Conclusion: In this representative Danish cohort, $13 \%$ of patients hospitalized with CAP received a DNR order. DNR orders were associated with higher mortality after adjustment for clinical risk factors. Thus, we encourage researcher to take DNR orders into account as potential confounder when reporting CAP associated mortality.
\end{abstract}

Keywords: Community-acquired pneumonia, Do not resuscitate orders, Mortality

\section{Background}

Do-not-resuscitate (DNR) orders are among, the most difficult clinical decisions. On the one hand, it is clearly not always in a patient's best interest to try to prolong a life with severe chronic disease and suffering. On the other hand, a DNR order documents a decision to

\footnotetext{
* Correspondence: gertrudbaknudsen@gmail.com;

Andreas.vestergaard.jensen.01@regionh.dk

'Department of Pulmonary and infectious medicine, Nordsjæellands Hospital, Dyrehavevej 29, 3400 Hillerød, Denmark

Full list of author information is available at the end of the article
}

withhold a potentially life-saving treatment and has been associated with excess mortality $[1,2]$. A better understanding of the associations between DNR orders and mortality could aid clinicians in these difficult decisions.

Community-acquired pneumonia (CAP) is one of the most common infectious diseases in the western world, especially in elderly patients [3-5]. All physicians, from primary to intensive care, will treat patients with CAP [6]. Mortality has been persistently high during the past decades and CAP is still a leading cause of mortality worldwide $[4,7-11]$. Older age, comorbidities and frailty

(c) The Author(s). 2020 Open Access This article is licensed under a Creative Commons Attribution 4.0 International License, which permits use, sharing, adaptation, distribution and reproduction in any medium or format, as long as you give appropriate credit to the original author(s) and the source, provide a link to the Creative Commons licence, and indicate if changes were made. The images or other third party material in this article are included in the article's Creative Commons licence, unless indicated otherwise in a credit line to the material. If material is not included in the article's Creative Commons licence and your intended use is not permitted by statutory regulation or exceeds the permitted use, you will need to obtain permission directly from the copyright holder. To view a copy of this licence, visit http://creativecommons.org/licenses/by/4.0/. The Creative Commons Public Domain Dedication waiver (http://creativecommons.org/publicdomain/zero/1.0/) applies to the data made available in this article, unless otherwise stated in a credit line to the data. 
contribute to the high mortality [12-15]. Given the high incidence, mortality and complicated mix of prognostic factors in patients with CAP, it is surprising that only few studies [16-19] have investigated the influence of DNR orders on clinical outcomes. In fact, previous studies have indicated that a DNR order is associated with mortality [19].

Therefore, when assessing the mortality for epidemiological or quality improvement purposes, it is possible that DNR orders should be considered as a potential independent risk factor for excess mortality in the large group of patients with CAP. Thus, in this study, we investigate the use of DNR orders in patients hospitalized with CAP and the association between DNR orders and mortality.

\section{Methods}

\section{DNR orders in Denmark}

In Denmark, the treating physician can write a DNR order if a patient is inevitably dying, severely disabled or in a vegetative state. DNR orders are also justified when a treatment might lead to survival with disease related consequences that are considered too severe or likely to cause suffering. The decision for a DNR order is primarily made by the treating physician. A patient cannot demand a certain treatment, including resuscitation. However, the patient can always refuse treatment, including resuscitation. This latter would also lead to a DNR order. Patients must be informed that a decision not to attempt resuscitation has been made. A DNR order is only valid for the current hospital admission and must be re-assessed upon a new admission unless the patient has written a living will refusing resuscitation [20].

\section{Study population and data collection}

We retrospectively included immunocompetent adult patients with CAP admitted to one of three hospitals; one regional and two local hospitals in North Zealand, Denmark from January 1st 2011 until June 30th 2012.

CAP was defined as a new infiltrate on the chest X-ray and at least one of the following symptoms of lower respiratory tract infection: cough, purulent expectoration, fever or pathological lung auscultation. Exclusion criteria were hospital admission within the last 28 days, active tuberculosis or immunosuppression. The in- and exclusion criteria are described in detail in [3].

All data stem from the electronic patient records as well as laboratory, microbiological and radiological databases. We registered data into the CAPNETZ database (www.capnetz.de) and locally into EpiData entry 3.1 (www.epidata.com). Details of this CAP-North cohort are described in [3].

\section{Outcome measures, exposures and confounders}

Our primary outcome was 30-day mortality. We grouped patients into no DNR order or DNR order. No DNR order was assumed when "full resuscitation" was stated in the patient record or resuscitation was not mentioned. We further grouped patients with a DNR order into early DNR (registered within $48 \mathrm{~h}$ of admission) or a late DNR order (registered $48 \mathrm{~h}$ or more after admission). We viewed age, nursing home residency, number of comorbidities (none, one or more than one), the CURB-65 score and admission to the intensive care unit (ICU) as potential confounders. The comorbidities registered in this study was COPD, other chronic respiratory disease, heart failure, other chronic heart disease, chronic kidney disease, chronic liver disease, neurological chronic disease, diabetes and malignancy.

The CURB-65 score was used as a grouped variable with three levels; CURB-65 score 0-1, CURB-65 score 2 and CURB-65 score $3-5$, corresponding to mild, moderate and severe pneumonia. In Denmark, people are mainly living at a nursing home if they are not able to take care of them self either due to old age, physical or mental health issues.

\section{Statistical methods}

Categorical variables were presented as percentages (counts) and continuous variables as medians (interquartile range (IQR)). Groups were compared with the Wilcoxon rank sum, the chi-square or the Fisher exact test. In comparisons of more than one group, we used the Kruskal-Wallis and the Chi-square test. $P$-values were adjusted for multiple comparisons using the Bonferroni correction.

We assessed the association between DNR orders and mortality with a Kaplan Meier curve and the log rank test and applied an adjusted cox proportional hazard model. The assumption of proportional hazard was assessed graphically and by assessing the martingale residuals. DNR order was included as a time dependent variable to overcome the risk of immortal time bias. Interaction analyses were performed to assess whether the effect of a DNR order was modified by other prognostic factors.

In patients with no DNR order, we tested for risk factors associated with 30-day mortality with the cox proportional hazard model. Variables significantly associated $(P<0.1)$ with 30 -day mortality in the crude analysis were included in the adjusted model.

We used SAS Enterprise Guide version 7.1 and GraphPad Prism 7.02.197 R2.

\section{Results}

Of the 1320 patients in the CAP-North cohort, DNR status could be assessed in 1317 patients; three patients 
were not included due to missing records. 13\% (177) had a DNR order; $8 \%$ (107) had an early and 5\% (70) a late DNR order. Patients with a DNR order were older $(82$ vs. 70 years, $p<0.001$ ), more frequently nursing home residents $(41 \%$ vs. $6 \%, \mathrm{p}<0.001)$ and had more comorbidities $(73 \%$ vs. $59 \%, \mathrm{p}<0.001)$. Patients with a DNR order were also more severely ill (CURB-65 score $\geq 3$; $50 \%$ vs $13 \%, p<0.001)$ and were more likely to be admitted to the ICU $(27 \%$ vs $7 \%, \mathrm{p}<0.001)$, Table 1 . All patients, regardless of DNR-status, received antibiotics upon admission. More patients with a DNR order

Table 1 Baseline characteristics according to do not resuscitate status

\begin{tabular}{|c|c|c|c|}
\hline & $\begin{array}{l}\text { No DNR order } \\
n=1140\end{array}$ & $\begin{array}{l}\text { DNR order } \\
n=177\end{array}$ & $P$-value \\
\hline Age, median (IQR) & $70(55-80)$ & $82(73-88)$ & $<0.001$ \\
\hline Sex, male & $47 \%(539)$ & $48 \%(85)$ & 0.85 \\
\hline Nursing home & $6 \%(73)$ & $41 \%(72)$ & $<0.001$ \\
\hline \multicolumn{4}{|l|}{ Comorbidities } \\
\hline COPD & $18 \%(200)$ & $24 \%(42)$ & 0.045 \\
\hline Oher chronic pulmonary disease & $13 \%(143)$ & $6 \%(11)$ & 0.014 \\
\hline Malignancy & $9 \%(101)$ & $10 \%(18)$ & 0.57 \\
\hline Chronic heart disease & $20 \%(223)$ & $32 \%(57)$ & $<0.001$ \\
\hline Chronic neurological disease & $12 \%(132)$ & $29 \%(51)$ & $<0.001$ \\
\hline Diabetes & $13 \%(144)$ & $10 \%(17)$ & 0.25 \\
\hline Chronic liver disease & $1 \%(9)$ & $2 \%(3)$ & 0.24 \\
\hline Chronic kidney disease & $3 \%(37)$ & $2 \%(4)$ & 0.48 \\
\hline \multicolumn{4}{|l|}{ Number of comorbidities } \\
\hline None & $41 \%(468)$ & $27 \%(48)$ & 0.001 \\
\hline One & $35 \%(395)$ & $41 \%(71)$ & 0.45 \\
\hline More than one & $24 \%(267)$ & $32 \%(56)$ & 0.05 \\
\hline \multicolumn{4}{|l|}{ Severity } \\
\hline CURB-65 0-1 & $59 \%(582)$ & $15 \%(22)$ & $<0.001$ \\
\hline CURB-65 2 & $28 \%(281)$ & $34 \%(49)$ & 0.43 \\
\hline CURB-65 3-5 & $13 \%(129)$ & $50 \%(72)$ & $<0.001$ \\
\hline ICU & $7 \%(79)$ & $27 \%(47)$ & $<0.001$ \\
\hline Intubation & $3 \%(35)$ & $12 \%(22)$ & $<0.001$ \\
\hline \multicolumn{4}{|l|}{ Antibiotic treatment ${ }^{a}$} \\
\hline Monotherapy penicillin ${ }^{b}$ & $47 \%(535)$ & $31 \%(54)$ & $<0.001$ \\
\hline Monotherapy other beta-lactam & $29 \%(332)$ & $36 \%(63)$ & 0.08 \\
\hline Combination therapy & $14 \%(163)$ & $24 \%(43)$ & 0.001 \\
\hline Other & $10 \%(110)$ & $10 \%(17)$ & 0.99 \\
\hline \multicolumn{4}{|l|}{ Mortality } \\
\hline 30-day & $4 \%(40)$ & $62 \%(109)$ & $<0.001$ \\
\hline 90-day & $6 \%(69)$ & $75 \%(133)$ & $<0.001$ \\
\hline 180-day & $9 \%(102)$ & $81 \%(143)$ & $<0.001$ \\
\hline
\end{tabular}

${ }^{a}$ Empiric therapy. ${ }^{b}$ benzylpenicillin or phenoxymethyl penicillin. COPD: chronic obstructive pulmonary disease. ICU: intensive care unit. IQR: interquartile range received combination therapy $(24 \%$ vs. $14 \%, p=0.001)$ and fewer small spectrum penicillin ( $31 \%$ vs $47 \%, p<$ 0.001).

Patients with an early DNR order were older (85 vs. $79, p=0.002)$ and more of them were nursing home residents (53 vs. $23, \mathrm{p}<0.001$ ) compared with patients with a late DNR order. Further, patients with an early DNR order were more severely ill upon admission (CURB-65 score $\geq 3: 59 \%$ vs. $38 \%, p=0.04$ ), but less likely to be admitted to the ICU (20\% vs $36 \%, p=0.03)$ compared with patients with a late DNR order. The number of comorbidities (one or more comorbidities; $75 \%$ vs. $69 \%, p=$ 0.78 ) was not significantly different between patients with early and late DNR orders (Table 2).

\section{Mortality}

Patients with a DNR order had higher short- and longterm mortality than patients without a DNR order (30day mortality: $62 \%$ vs. $4 \%$ and 180 -day mortality: $81 \%$ vs. $9 \%, p<0.001)$, Fig. 1 .

In the cox proportional hazard model, adjusted for age, comorbidities, CURB-65 score, nursing home residency and ICU admission, a DNR order remained significantly associated to 30-day mortality. The interaction between the CURB-65-score and DNR order was significant $(p=0.02)$. The association between a DNR order and 30-day mortality was strongest in patients with low CURB-65 score hazard ratio (HR) 32.4 (95\% CI 8.5123), HR 26.6 (95\% CI 12.5-56.7) and HR 9.4 (95\% CI 4.7-19) for CURB-65 score $0-1,2$ and 3-5, respectively. Patients with an early DNR order had lower 30- and 180-day mortality than patients with a late DNR order (30-day: $57 \%$ vs. $69 \%, p=0.12$; 180 -day: $77 \%$ vs $87 \%$, yet the difference was not statistically significant $(P=0.08)$. Time from admission to death was median 12 days (IQR: 8-24) in patients with a late DNR order compared with median 10 days (IQR; 2-32) for patients with an early DNR order $(p=0.05)$. In patients with a late DNR order, the order was documented in the record after a median of six days (IQR: 4-13) and the median time from receiving a DNR order to death was 4 days (IQR: 1-9). As a sensitivity analysis we tested the association between an early DNR order and mortality by applying the cox proportional hazard model while ignoring the late-DNR orders which resulted in a HR $3.64(95 \% \mathrm{CI}$ 2.48-5.36).

\section{Risk factors for 30-days mortality in patients without a DNR order}

Patients without a DNR order had a 30-day mortality rate of $4 \%$. In the unadjusted cox-regression analysis age, nursing home residency, CURB-65 score and number of comorbidities were all significantly associated with 30day mortality in patients without a DNR order. In the 
Table 2 Baseline characteristics according to early or late do not resuscitate order

\begin{tabular}{|c|c|c|c|}
\hline & $\begin{array}{l}\text { Early DNR order } \\
n=107\end{array}$ & $\begin{array}{l}\text { Late DNR order } \\
n=70\end{array}$ & $\boldsymbol{p}$-value \\
\hline Age, median (IQR) & $85(76-89)$ & $79(72-85)$ & 0.001 \\
\hline Sex, male & $46 \%(49)$ & $51 \%(36)$ & 0.46 \\
\hline Nursing home & $53 \%(56)$ & $23 \%(16)$ & $<0.001$ \\
\hline \multicolumn{4}{|l|}{ Comorbidities } \\
\hline COPD & $22 \%(23)$ & $27 \%(19)$ & 0.43 \\
\hline Oher chronic pulmonary disease & $6 \%(6)$ & $7 \%(5)$ & 0.68 \\
\hline Malignancy & $11 \%(12)$ & $9 \%(6)$ & 0.57 \\
\hline Chronic heart disease & $38 \%(41)$ & $23 \%(16)$ & 0.03 \\
\hline Chronic neurological disease & $33 \%(35)$ & $23 \%(16)$ & 0.16 \\
\hline Diabetes & $7 \%(8)$ & $13 \%(9)$ & 0.24 \\
\hline Chronic liver disease & 0 & $4 \%(3)$ & 0.03 \\
\hline Chronic kidney disease & $3 \%(3)$ & $1 \%(1)$ & 0.55 \\
\hline \multicolumn{4}{|l|}{ Number of comorbidities } \\
\hline None & $25 \%(26)$ & $31 \%(22)$ & 0.99 \\
\hline One & $40 \%(42)$ & $41 \%(29)$ & 1.00 \\
\hline More than one & $35 \%(37)$ & $27 \%(19)$ & 0.78 \\
\hline \multicolumn{4}{|l|}{ Severity } \\
\hline CURB-65 0-1 & $11 \%(9)$ & $22 \%(13)$ & 0.46 \\
\hline CURB-65 2 & $31 \%(26)$ & $40 \%(23)$ & 0.78 \\
\hline CURB-65 3-5 & $59 \%(50)$ & $38 \%(22)$ & 0.04 \\
\hline ICU & $20 \%(22)$ & $36 \%(25)$ & 0.03 \\
\hline Intubation & $4 \%(4)$ & $26 \%(17)$ & $<0.001$ \\
\hline \multicolumn{4}{|l|}{ Antibiotic treatment ${ }^{a}$} \\
\hline Monotherapy penicillin ${ }^{b}$ & $31 \%(33)$ & $30 \%(21)$ & 0.91 \\
\hline Monotherapy other betalactam & $33 \%(35)$ & $40 \%(28)$ & 0.32 \\
\hline Combination therapy & $26 \%(28)$ & $21 \%(15)$ & 0.47 \\
\hline Other & $10 \%(11)$ & $9 \%(6)$ & 0.71 \\
\hline \multicolumn{4}{|l|}{ Mortality } \\
\hline 30-day & $57 \%(61)$ & $69 \%(48)$ & 0.12 \\
\hline 90-day & $72 \%(77)$ & $80 \%(56)$ & 0.23 \\
\hline 180-day & $77 \%(82)$ & $87 \%(61)$ & 0.08 \\
\hline
\end{tabular}

${ }^{\mathrm{a} E m p i r i c}$ therapy. ${ }^{\mathrm{b}}$ benzylpenicillin or phenoxymethyl penicillin

$C O P D$ chronic obstructive pulmonary disease, ICU intensive care unit, IQR interquartile range

adjusted analysis only nursing home residency and CURB-65-score 3-5 remained significantly associated with 30-day mortality, HR 6.0 (95\% CI: 2.6-13.9, $p<$ 0.001 ) and HR 3.6 (95\% CI: 1.1-11.0, $p=0.03)$, respectively (Table 3 ).

\section{Discussion}

In this cohort of patients hospitalized with CAP, 13\% had received a DNR order during hospital admission. More than half received a DNR order during the first two days and again more than half of these died within 30 days. DNR orders were, independent of known risk factors, associated with increased mortality. Conversely, the mortality of patients without DNR orders was markedly lower. Here nursing home residency and severe CAP were significantly associated with an increased risk of mortality.

Surprisingly, only few other studies have described the occurrence of DNR orders in patients with CAP. Similar to our findings, in a US study of 90,644 pneumonia cases from 303 hospitals in California the median DNR-rate was $15.8 \%$ [18]. Another US study of 1339 hospitalised CAP patients found that $22 \%$ had a DNR order [16]. Further, a Japanese study of 641 




CAP patients 65 years of age or older found a DNRrate of $29 \%$ in line with findings from a prospective cohort study of 1093 elderly patients hospitalized with CAP from the Netherlands reporting a DNR-rate of $27,1 \%[17,19]$. The differences can be due to a larger burden of comorbidities and higher age. Yet, cultural and legislative differences probably also play an important role, which underlines the importance of studying DNR orders in this common group of patients in different settings [21].

As previous researchers $[16,17,22]$, we found that almost three quarters of deaths during 30 days were among patients with a DNR order. Even after adjustment for clinical risk factors, patients with a DNR order had an increased risk of both short- and longterm mortality. Walkey et al. [18] also report this association after adjustment for demographics, comorbidities and acute organ failure. This indicates that DNR orders are an important factor to consider when assessing mortality in CAP.

While DNR orders evidently are associated with mortality, some findings warrant further exploration. The association between DNR orders and mortality was strongest in patients with a low CURB-65 score. One explanation for this finding could be that the treating physicians included in their assessment of the patients factors not accounted for in the CURB-65 score such as comorbid conditions and frailty.

Table 3 Risk factors associated with 30-day mortality in patients with no DNR order

\begin{tabular}{|c|c|c|c|c|}
\hline & \multicolumn{2}{|l|}{ Crude } & \multicolumn{2}{|l|}{ Adjusted } \\
\hline & $\mathrm{HR}(\mathrm{Cl})$ & $P$-Value & $\mathrm{HR}(\mathrm{Cl})$ & $P$-Value \\
\hline Age & $1.5(1.2-1.9)$ & 0.001 & $1.0(0.97-1.04)$ & 0.9 \\
\hline Nursing home residency & $8.9(4.6-17.0)$ & $<0.001$ & $6.0(2.6-13.9)$ & $<0.001$ \\
\hline \multicolumn{5}{|l|}{ CURB-65 score } \\
\hline $0-1$ (ref) & - & - & - & - \\
\hline 2 & $3.9(1.6-9.98)$ & 0.004 & $2.8(0.99-8.02)$ & 0.05 \\
\hline $3-5$ & $7.3(2.8-18.9)$ & $<0.001$ & $3.6(1.1-11.0)$ & 0.03 \\
\hline \multicolumn{5}{|l|}{ Number of comorbidities } \\
\hline None (ref) & - & - & - & - \\
\hline One & $2.9(1.2-7.1)$ & 0.02 & $1.5(0.6-4.1)$ & 0.35 \\
\hline More than one & $3.6(1.5-8.9)$ & 0.006 & $2.0(0.7-5.2)$ & 0.18 \\
\hline
\end{tabular}

Number of cases used in the adjusted analysis: 981 . HR: hazard ratio. Cl: confidence interval 
Marrie et al. [16] hypothesized that late DNR orders represent a lack of response to treatment whereas they assumed that early DNR orders rather reflect comorbidities and the general health status of a patient. Accordingly, we found that patients with early DNR orders were older and more often nursing home residents. In addition, patients with late DNR orders in our study were more likely to be transferred to the ICU and treated with mechanical ventilation. We did not find a significant difference in the number of comorbidities in patients with late and early DNR orders, albeit there was a tendency towards a higher burden in patients with early DNR orders. Thus, our results largely support the findings by Merrie et al. Since a late DNR order could in some cases represent treatment failure it is possible that including late DNR orders would lead to an overestimation of the association between a DNR order and mortality. Therefore, we performed a sensitivity analysis where patients with a late DNR order were grouped with patients with no DNR order. In the sensitivity analysis an early DNR order remained significantly associated with a higher mortality risk underlining that a DNR order is associated with a higher mortality risk.

An independent association between DNR orders and mortality has previously been demonstrated in other areas of medicine, including patients with septic shock and patients with acute surgical disorders $[1,2,23]$. This leaves the question whether patients with a DNR order died because they received less aggressive and/or inferior treatment or that a DNR order rather mirrors the natural history of CAP in fragile patients. In septic patients with DNR orders, Sakari et al. [2] recorded fewer invasive procedures indicating less aggressive treatment. Further, previous studies investigating physicians' interpretation of DNR orders have shown that they are misinterpreted to mean that essential steps of treatment such as contacting a doctor upon deterioration, fluid resuscitation and other supportive treatment, may be omitted [24-27]. Furthermore, a DNR order has previously been identified as a negative predictor for ICU admission [28].

In our study patients with CAP with a DNR order did not receive inferior antibiotic treatment or fewer ICU admissions which was also the conclusion from the study by Mulder et al., who concluded that treatment restrictions were not associated with empirical antibiotic treatment in patients with CAP [19]. Thus, we cannot conclude, based on our study, that the excess mortality of patients with a DNR order was caused by inferior treatment. In principle, we cannot exclude that all the patients in our cohort died of a cardiac arrest and thus indirectly of a DNR. However, we find this scenario unlikely. Instead we assume that a DNR order often is a proxy of advanced underlying disease and/or frailty that is not in captured by other established risk factors for mortality.
In a post-hoc analysis, we investigated whether risk factors for mortality in patients with no DNR order differed from those generally found among patients with CAP. We found nursing home residency and disease severity to be risk factors among this group, which is previously reported as important risk factors [3, 12].

The retrospective design is the major limitation of our study because we had to rely on existing data in the patient records. On the other hand, we included all patients with CAP in an entire geographic region thus reducing the risk of selection bias. Obviously, the inclusion of patients with the entire prognostic spectrum is important in a study like ours and we are confident that it reflects "real life" without focus on study patients or adherence to specific treatment regimens. Confounding by indication is a concern because physicians likely are more prone to consider a DNR order in severely ill patients potentially leading to an overestimation of the association between DNR orders and mortality. We could not determine in the patient records whether not registering a DNR order was an active choice or merely lack of consideration and we do not know the reason for issuing a DNR order. In addition, we lack data on other treatment limitations such as refraining from intubation and/or admission to the ICU, e.g. some admissions to the ICU could have been for monitoring of inotropic treatment, but not for intubation and cardiopulmonary resuscitation. Whether to consider ICU admission as a confounder may be controversial as some patients may have had an order of no ICU admission and in these cases, it may be considered an intermediate instead. However, as nearly one third of the patients with a DNR order received treatment in the ICU we chose to include it as a confounder. As we lack data on the severity off the individual comorbidities, we have chosen to include them in our model as a grouped variable. There is a risk off residual confounding with this approach, which could have caused us to overestimate the effect of a DNR order.

\section{Conclusion}

In conclusion, a DNR order is an independent risk factor for mortality in patients hospitalized with CAP. Thus, a DNR order is a potential confounder to consider when reporting risk factors for mortality in CAP that has not been taken into account in previous studies. Based on our findings we encourage researchers to account for DNR orders when reporting CAP associated mortality.

\section{Abbreviations \\ CAP: Community-acquired pneumonia; DNR: Do-not-resuscitate; HR: Hazard ratio; ICU: Intensive care unit; IQR: Interquartile range; LRTI: Lower respiratory} tract infection

\section{Acknowledgements}

The authors would like to thank the CAPNETZ stiftung, the CAPNETZ study group and the Pneumonia Research Group - Nordsjællands Hospital including research nurse Gudrun Kaldran and M.D. Sara Falk Jensen. Further, 
the authors would like to thank dr. Zoe Fritz for commenting on the manuscript.

\section{Authors' contributions}

GBE had full access to all the data in the study and takes responsibility for the integrity of the data and the accuracy of the data analysis. Study concept and design: GBE, AVJ, PTP, SBA, BLØ, GR, PR and CP. Acquisition, analysis, or interpretation of the data: GBE, AVJ, PTP, SBA, BL $\varnothing, G R, P R$ and $C P$. Drafting of the manuscript: GBE, AVJ, PR, CP. Critical revision of the manuscript for important intellectual content: GBE, AVJ, PTP, SBA, BLØ, GR, PR and CP. Statistical analysis: GBE. All authors have read and approved the final manuscript.

\section{Funding}

The study was supported by the Research council, Nordsjællands Hospital. The funding body did not played a role in the design of the study or collection, analysis, or interpretation of data or writing the manuscript.

\section{Availability of data and materials}

The datasets used and analyzed during the current study area available from the corresponding author in reasonable request.

\section{Ethics approval and consent to participate}

The study was approved by the Danish Health and Medicines Authority (33013-340/1/) and by the Danish Data Protection Agency (HIH-2013-017). Danish legislation does not require informed consent for register-based studies.

\section{Consent for publication}

Not applicable.

\section{Competing interests}

Dr. Rohde reports personal fees from Pfizer, Boehringer Ingelheim, Solvay, GSK, Essex Pharma, MSD and Novartis for lectures including service on speaker's bureaus outside the submitted work and personal fees from GSK for travel/accommodations/meeting expenses, outside the submitted work. Dr. Ravn reports personal fees from MSD, Abb Vie and CSL Behring as invited speaker, outside the submitted work. Dr. Ravn reports personal fees from Statens Serum Institute as data safety monitoring board member, outside the submitted work. Dr. Ravn reports non-financial research collaboration with Astellas outside the submitted work.

The remaining authors declare no other conflict of interest.

\section{Author details}

${ }^{1}$ Department of Pulmonary and infectious medicine, Nordsjællands Hospital, Dyrehavevej 29, 3400 Hillerød, Denmark. ${ }^{2}$ University of Copenhagen, Faculty of Health and Medical Sciences, Copenhagen, Denmark. ${ }^{3}$ CAPNETZ-Stiftung, Hannover Medical School, Hanover, Germany. ${ }^{4}$ Department of Infectious Diseases, Amager Hvidovre Hospital, Hvidovre, Denmark. ${ }^{5}$ Department of Respiratory Medicine, Medical Clinic I, Goethe University Hospital, Frankfurt, Germany. ${ }^{6}$ Department of Medicine, Unit for Infectious Diseases, Herlev Gentofte Hospital, Hellerup, Denmark. ${ }^{7}$ Institute for Clinical research University of Southern Denmark, Campusvej 55, DK-5230 Odense M, Denmark. ${ }^{8}$ Unisanté Rue du Bugnon 44, CH-1011, Lausanne, Switzerland.

Received: 30 August 2019 Accepted: 15 July 2020

\section{Published online: 24 July 2020}

\section{References}

1. Scarborough JE, Pappas TN, Bennett KM, Lagoo-Deenadayalan S. Failure-topursue rescue: explaining excess mortality in elderly emergency general surgical patients with preexisting "do-not-resuscitate" orders. Ann Surg. 2012;256(3):453-61.

2. Sarkari NN, Perman SM, Ginde AA. Impact of early do-not-attemptresuscitation orders on procedures and outcomes of severe sepsis. J Crit Care. 2016;36:134-9.

3. Egelund GB, Jensen AV, Andersen SB, Petersen PT, Lindhardt BO, von Plessen $C$, et al. Penicillin treatment for patients with community-acquired pneumonia in Denmark: a retrospective cohort study. BMC Pulm Med. 2017; 17(1):66 -017-0404-8
4. Welte T, Torres A, Nathwani D. Clinical and economic burden of community-acquired pneumonia among adults in Europe. Thorax. 2012; 67(1):71-9.

5. Trotter CL, Stuart JM, George R, Miller E. Increasing hospital admissions for pneumonia. England Emerg Infect Dis. 2008;14(5):727-33.

6. Wunderink RG, Waterer G. Advances in the causes and management of community acquired pneumonia in adults. BMJ. 2017;358:j2471.

7. Sogaard M, Nielsen RB, Schonheyder HC, Norgaard M, Thomsen RW. Nationwide trends in pneumonia hospitalization rates and mortality, Denmark 1997-2011. Respir Med. 2014;108(8):1214-22.

8. Singanayagam A, Chalmers JD, Welte T. Epidemiology of CAP in Europe. In: Chalmers JD, Pletz MW, Aliberti S, editors. European respiratory monograph Community-Acquired Pneumoni.: European Respiratory Society; 2014.

9. Ewig S, Torres A. Community-acquired pneumonia as an emergency: time for an aggressive intervention to lower mortality. Eur Respir J. 2011;38(2):253-60.

10. Ewig S, Birkner N, Strauss R, Schaefer E, Pauletzki J, Bischoff H, et al. New perspectives on community-acquired pneumonia in 388406 patients. Results from a nationwide mandatory performance measurement programme in healthcare quality. Thorax. 2009;64(12):1062-9.

11. World Health Organization. WHO Top 10 causes of death. Accessed 27 March 2018; Available at: http://www.who.int/gho/mortality_burden disease/causes_death/top_10/en/.

12. Lim WS, van der Eerden MM, Laing R, Boersma WG, Karalus N, Town Gl, et al. Defining community acquired pneumonia severity on presentation to hospital: an international derivation and validation study. Thorax. 2003;58(5): 377-82.

13. Holter JC, Ueland T, Jenum PA, Muller F, Brunborg C, Froland SS, et al. Risk factors for long-term mortality after hospitalization for community-acquired pneumonia: a 5-year prospective follow-up study. PLoS One. 2016;11(2): e0148741.

14. Fine MJ, Auble TE, Yealy DM, Hanusa BH, Weissfeld LA, Singer DE, et al. A prediction rule to identify low-risk patients with community-acquired pneumonia. N Engl J Med. 1997;336(4):243-50.

15. Luna CM, Palma I, Niederman MS, Membriani E, Giovini $V$, Wiemken $T L$, et al. The impact of age and comorbidities on the mortality of patients of different age groups admitted with community-acquired pneumonia. Ann Am Thorac Soc. 2016;13(9):1519-26.

16. Marrie TJ, Fine MJ, Kapoor WN, Coley CM, Singer DE, Obrosky DS. Community-acquired pneumonia and do not resuscitate orders. J Am Geriatr Soc. 2002:50(2):290-9.

17. Oshitani $Y$, Nagai H, Matsui H. Rationale for physicians to propose do-notresuscitate orders in elderly community-acquired pneumonia cases. Geriatr Gerontol Int. 2014;14(1):54-61.

18. Walkey AJ, Weinberg J, Wiener RS, Cooke CR, Lindenauer PK. Association of do-not-Resuscitate Orders and Hospital Mortality Rate among Patients with Pneumonia. JAMA Intern Med. 2016;176(1):97-104.

19. Mulder $\mathrm{T}$, van Werkhoven $\mathrm{CH}$, Huijts SM, Bonten MJ, Postma DF, Oosterheert JJ. Treatment restrictions and empirical antibiotic treatment of community-acquired pneumonia in elderly patients. Neth J Med. 2016;74(1):56.

20. Sundhedsstyrelsen soæ. Vejledning om forudgående fravalg af livsforlængende behandling, herunder genoplivningsforsøg, og om afbrydelse af behandling. updated Oct 2016. Accessed Apr 2018.; Available at: http:// www.ft.dk/samling/20161/almdel/suu/spm/71/svar/1357457/1685727.pdf.

21. Tabak YP, Johannes RS, Silber JH, Kurtz SG. Should do-not-resuscitate status be included as a mortality risk adjustor? The impact of DNR variations on performance reporting. Med Care. 2005;43(7):658-66.

22. Chalmers JD, Singanayagam A, Hill AT. Systolic blood pressure is superior to other haemodynamic predictors of outcome in community acquired pneumonia. Thorax. 2008:63(8):698-702.

23. Bradford MA, Lindenauer PK, Wiener RS, Walkey AJ. Do-not-resuscitate status and observational comparative effectiveness research in patients with septic shock*. Crit Care Med. 2014;42(9):2042-7.

24. Beach MC, Morrison RS. The effect of do-not-resuscitate orders on physician decision-making. J Am Geriatr Soc. 2002;50(12):2057-61.

25. Henneman EA, Baird B, Bellamy PE, Faber LL, Oye RK. Effect of do-notresuscitate orders on the nursing care of critically ill patients. Am J Crit Care. 1994;3(6):467-72.

26. Moffat S, Skinner J, Fritz Z. Does resuscitation status affect decision making in a deteriorating patient? Results from a randomised vignette study. J Eval Clin Pract. 2016;22(6):917-23. 
27. Fritz Z, Fuld J, Haydock S, Palmer C. Interpretation and intent: a study of the (mis)understanding of DNAR orders in a teaching hospital. Resuscitation 2010;81(9):1138-41.

28. Cohen RI, Lisker GN, Eichorn A, Multz AS, Silver A. The impact of do-notresuscitate order on triage decisions to a medical intensive care unit. J Crit Care. 2009;24(2):311-5.

\section{Publisher's Note}

Springer Nature remains neutral with regard to jurisdictional claims in published maps and institutional affiliations.

- fast, convenient online submission

- thorough peer review by experienced researchers in your field

- rapid publication on acceptance

- support for research data, including large and complex data types

- gold Open Access which fosters wider collaboration and increased citations

- maximum visibility for your research: over $100 \mathrm{M}$ website views per year

At $\mathrm{BMC}$, research is always in progress. 